\title{
Conflitos no Espaço das Normas de DIP. - Renúncia e Devolução.
}

\author{
Haroldo Valladão \\ (Catedrático da Faculdade Nacional de \\ Direito).
}

\begin{abstract}
SUMÁrIO: 1. A divergência espacial das normas de DiP. Conflitos posítivos e negativos de normas de DIP. 2. Critério geral de solução. 3. O conflito positivo. Soluções doutrinárias, legislativas, jurisprudenciais e convencionais. 4. Conclusão do autor. 5. O conflito negativo. 6. Evolução doutrinária. 7. Direito brasileiro. 8. A cópia pela Lei de Introd. do direito italiano e a reação nacional. 9. Anteprojeto brasileiro. 10. Opinião do Autor. 11. Conclusão.
\end{abstract}

1. As normas de DIP possuem, quais outras normas jurídicas, também o problema de sua aplicação espacial.

Tendo cada Estado, cada Estado membro, etc. suas próprias normas de DIP, segundo já vimos antes, podem elas, também, entrar em conflito no espaço, já então, de segundo grau ${ }^{1}$.

1. H. Valladäo, A Devolução nos Conflitos sôbre a Lei Pessoal, São Paulo, 1929/1930, tese à Docência Livre, também publicada, na integra, na Revista de Direito Civil e Comercial. (Bento DE FARIA) 96, ps. 10,247 e 517 ; Estudos, ps. 29, 78, 132, 415/1, 628; DIP in Delta Larousse, ns. VIII e XV; Le Renvoi in DIP, Ann. de L'Institut Dir. Int., 1957, 47, II, ps. 82/92, 1961, 49, II, ps. 316/8; $A$ Lei de Intr. Cód. Civ. e sua Reforma, folheto, R.T.Y.P. 292/7, Rev. For., 185/21, etc.; Anteprojeto Lei Geral. arts. $76 / 7$ e Justificação, ps. 114/8. A bibliografia, no assunto, é vastíssima; consta dos tra- 
E, assim, os fatos e as relações entram em conexão, espacialmente, com normas autônomas e divergentes de DrP.

Mas êsses novos conflitos de leis, agora de disposições legistivas de DIP, são da mesma natureza dos anteriormente examinados de textos legais civis, comerciais, processuais, são sempre conflitos de leis no espaço ${ }^{2}$. Constituem os conflitos positivos e negativos de regras de Drp, que estudamos, conjunta e sucessivamente, fixando rumos, desde 1929 (Valladão, A Devolução. ps. 9 e ss.) e, agora, procuramos solucionar lado a lado (arts. 76 e 77 do Anteprojeto de Lei Geral), mantendo e aperfeiçoando aquelas diretrizes.

2. Continuamos a sustentar que tais conflitos de leis de DIP. devem ser resolvidos procurando, para a espécie, a lei mais apropriada, com o mesmo espírito de justiça, eqüidade e harmonia que propugnamos para solucionar os conflitos de leis civis, comerciais, processuais, etc.

Divergindo as leis de DIP. do fôro e estranha, o legislador e o juiz procurarão, qual fazem numa contrariedade de leis civis, aquela que melhor deverá reger a espécie.

balhos acima e de qualquer obra geral de DiP. Da clássica monografia de PотU, La Question du Renvoi, Paris, 1915, ao recente e importante livro de PH. Franceskakis, La Theorie du Renvoi, Sirey, 1958, citem-se, entre vários, os cursos na Haia, de Lewald. Recueil, 29/519, de MAURY, 57/518 e de BALOGH, 57/621 e 688, o magnífico trabalho de crítica da jurisprudência italiana de M. Philonenko, La Théorie du Renvoi in Dir. Comparé, 1935, o relevante ensaio de Alessandro T. DE Vignano, Note Critiche.. in Tema di Rinvio, as agudíssimas observações de DE Nova in Dir. Internaz., 1960, n. 3, R. QUADRI in Dir. Intern., 1959, 110 e de LOUIS LUCAS recentíssimas, Roma 1964/1 e ss.. Leiam-se, ainda, no An. Int. Dr. Int., 1947/II, 1/125, o Relat. do eminente Prof. Georges MARIDAKIS, e as observações de outros membros e associados.

2. Antes o fizera, segundo ali acentuamos, ANzmotri, Studi Critici, 1898, 241/2, e, mais remotamente, voN BAR., Th. Prax. des IPR, 1889, § 94, e, ainda, KAHN, Abhandlungen, I, após 1920, LEWALD in Recueil, cit., 29, NIBOYET, Manuel, ns. 394 e ss., e após a última guerra, BATIFFOL, n. 299 e nota, e, ùltimamente, Franciskakis, La Théorie, ns. 56 e ss.. 
E rechassamos, assim, a opinião radical das escolas apriorísticas, logicistas e chauvinistas, segundo as quais o juiz do fôro deverá aplicar sempre e exclusivamente a sua lei de DIP., que seria, pois, de rigorosa ordem pública internacional, de caráter absoluto, internacional e universalista, ignorando, para todos os efeitos, a lei de DIP. estranho.

Êsse totalitarismo da lex fori consistiria em reacionária marcha à ré na vocação indiscutível do DIP de considerar e respeitar a lei estrangeira, harmonizando e balanceando, com justiça e eqüidade, as leis em conflito do fôro e de outro sistema jurídico.

O ideal, aliás, da comunidade do direito entre os povos (SAVIGNY) não poderia ficar limitado e restrito às diferentes leis civis, e ser excluído das diversas leis de DrP.

3. A divergência espacial entre normas de nrP. levanta um conflito positivo, à semelhança do que ocorre no direito processual quando cada uma indica o seu próprio direito para reger a espécie com elas conetada.

Assim o antigo juiz norte-americano ou o italiano para decidirem, respectivamente, questão de direitos reais sôbre bens móveis pertencentes a domiciliados nos Estados Unidos ou a italianos, mas móveis sitos no Chile ou no Brasil, teriam de sujeitá-los pelo antigo pIP. dos Estados Unidos (Story, § 376) ou da Itália (Cod. Civ. 1865, D.P.L.G., art. 7..$\left.^{\circ}\right)$ à lei norte-americana ou italiana, do domicílio ou da nacionalidade do proprietário, enquanto pelo DIP. chileno (Cód. Civ., art. 16) ou brasileiro (Intr., 10, e L. Intr., 8) seriam regidos pela lei chilena ou pela lei brasileira, lei da respectiva situação. Paralelamente, o atual juiz brasileiro ou italiano, para decidir sôbre a sucessão de uma pessoa domiciliada no Brasil ou de nacionalidade italiana deixando bens imóveis sitos na Inglaterra ou nos Estados Unidos, teriam de sujeitá-los pelo DIP. brasileiro (L. I., art. 10) ou da Itália (Cód. Civ., D.P. 1865, art. 8., 1942 , art. 23) à lei brasileira ou italiana, domícilio ou da nacionalidade, enquanto pelo DIP. da Inglaterra (DiceY, Rule 127) ou dos Estados Unidos 
(SToRy, § 483) e Restatement, §§ 245 e 249) estariam sujeitos à lei inglêsa ou norte-americana, da respectiva situação. Igualmente o juiz brasileiro para decidir da capacidade, dos direitos de família e de sucessões de um português domiciliado no Brasil aplicaria pelo DIP. do Brasil (L. I. art. 10) a lei brasileira do domicilio, enquanto pelo DIP. de Portugal (Cód. Civ., art. 24 e jurisprudencial) seria competente a lei portuguêsa, da nacionalidade.

Para as escolas "aprioristas" o juiz do fôro aplicará "indiscutivelmente" a sua lei de DiP., resultando daí "um conflito que a ciência não pode resolver" (v. Bar, § 94); "as regras de DIP. formuladas nas leis internas de cada Estado constituem para êsse Estado o verdadeiro direito internacional", que "é para êste uno e absolutamente exclusivo do direito internacional dos outros Estados, cujas leis são como se não existissem e se apagam completamente" (Machado Vilela, $O$ Dip no Cód. Civ. Br., 1921, p. 438), apoiando-se em Pillet para quem "A défaut d'une souveraineté superieure. il ne peut évidemment appartenir qu'a l'Est de tracer lui-même les limites de sa souveraineté et de la souveraineté d'autre sur son territoire" e seria uma "absurdité" que um Estado abandonasse a outro "lei soin d'indiquer où va sa propre souveraineté", Principes, 1903 , ns. 62 e 66) ; "le conflit. est insoluble (Lewald, Rec. 29/532). Parce que ce sont des conflits de souverainetés. . chaque étant independent il n'y a pas de raison pour que l'une s'incline devant autre" (Niboyet, Manuel ${ }^{3}$, p. 407). Assim continuam a pensar Batiffol ${ }^{4}$, p. 300) e Franceskakis (n. 57), e, sem o mesmo apriorismo, Anzilotit (4) e Maury in Recueil, 57/526.

3. Mesmo para os raríssimos casos em que a norma do DIP desse uma solução direta, é claro que ainda poderia surgir um conflito interespacial, entre tal disposição e outra de DIP normal, isto é, indireta, conetadas com o caso, em foro diverso.

4. ANZILotTi justificava a aplicação sempre do DiP do fôro em face dos têrmos expressos das regras de conflitos italianos, das DIP que, de acôrdo com a escola manciniana, tinham uma vocação absoluta, universal, p. ex., o art. $8 .^{\circ}$, DIP 1865 (Curso, p. 103). 
Mas os juristas conscientes das realidades, objetivos, os legisladores e os tribunais procederam mui diversamente: verificaram a existência de divergência entre as regras de DiP., e procuraram, também, resolvê-la com critérios de harmonia e justiça.

Já no DIP do Código da Áustria, no ABGB de 1811, encontra-se uma regra de DIP que se limita expressamente para não invadir a área do DIP estrangeiro: assim o art. 34 após proclamar que as leis civis obrigam todos aquêles para quem foram promulgadas declara que os cidadão (austríacos) ficam sujeitos às limitações de sua capacidade pessoal por tais leis, mesmo pelos atos e negócios que realizam fora do território na medida em que tais atos e negócios possam produzir conseqüências na Áustria. Ėsse salutar princípio, que reconhece em parte o DrP estrangeiro, foi acolhido no Cód. do Chile, art. 15, $1^{\circ}$, subordinando os chilenos no estrangeiro às leis sôbre estado e capacidade para os atos que tenham de produzir efeito no Chile; no de Portugal, art. 24, sujeitando os portuguêses que viajam ou residem em país estrangeiro às leis portuguêsas concernentes à sua capacidade civil, ao seu estado e à sua propriedade imobiliária situada no reino, enquanto aos atos que houverem de produzir nele os seus efeitos; e finalmente, com amplitude, no Cód. do México (1870), para estado e capacidade dos mexicanos, art. 13, forma dos atos mexicanos ou estrangeiros fora do Estado, art. 15, obrigações e contrato de mexicanos no estrangeiro, art. 17, "respecto de atos que deban ejecutarse no todo o en parte" no México.

E StoRy ao formular as regras de DIP de que os bens móveis (personal property) regem-se pela lei do domícilio do proprietário estabeleceu logo a exceção, a menos que lei positiva ou costumeira local dispuzesse diversamente em casos especiais, fazendo prevalecer a lex rei sitae (383) citando acórdão da Suprema Côrte da Luisiania $(\$ \$ 390,392$, $395)$. Eis ai uma solução feliz, conciliadora, em que o prin- 
cípio de DIP da lei do domicílio para os móveis cede, renuncia ao se encontrar com outro diverso, da lei da situação do móvel ${ }^{5}$.

Essa posição conciliadora num conflito positivo de normas de DIP passou nos Estados Unidos para o campo legislativo, adotada que foi no primeiro Cód. Civil da Califórnia de 1872 (suprimida, 1873, restabelecida, 1875) e até hoje em vigor, Cód. 1949, sempre no mesmo $\S 946$, dispondo que "não havendo lei em contrário no lugar da situação da propriedade (personal or movable property) ela seguirá a pessoa do seu proprietário e é governada pela lei do seu domicílio"; êsse Código influenciou outros que repetiram a regra com outras palavras, Idaho, $\S 55$, Montana, $\S 67$, North Dakota, 947, Oklahoma, $\S 311$, Zona do Canal, $\S 361$, Guam, $\S 971^{6}$.

No mesmo assunto, o Código da Itália, de 1865, D.P., art. $7 .^{\circ}$, consolidou norma semelhante em que acata o DIP estrangeiro, prevendo uma possível colisão com o do fôro, pois determina que "Os bens móveis estão sujeitos às leis da nação do proprietário salvo disposições contrárias da lei do país em que se encontrem" "

Aliás a cláusula final da regra de DIP italiana, do art. $8 .^{\circ}$ daquele Código mandando reger a sucessão pela lei nacional do de cujus "qualquer que seja a natureza dos bens e em qualquer país em que se encontrem" teve uma interpretação profundamente restritiva dos tribunais italianos, assente até 1906, Côrtes de Cassação de Turim, 22/12/1878, e de Palermo, 25/8/1894 que analisamos e elogiamos pela

5. No mesmo sentido LORENZEN, in Repertoire VI, n. 138.

6. Também no Baixo Canadá onde o Código de Quebec impõe a lei do domicílio do proprietário para os móveis a jurisprudência e a doutrina limitam-na quando o bem está noutro lugar onde impera a lex rei sitae (JoHNSON, II, p. 22 e ss. com o caso Nugents al. v. Canadian Rock Products) e CASTELL, p. 161.

7 Fedozzi demonstrou, irretorquìvelmente (op. eit., p. 645) que, no ressalvar o legislador italiano de DiP (lei nacional) mandou aplicar - DIP (lex rei sïtae) estrangeiro. 
sua objetividade desde $1929^{8}$, aprovada por grande parte da doutrina italiana com GaBba, G.F. à frente ${ }^{9}$ e louvada por sua realidade e justiça, a seguir, 1935, por PhiLonenko ${ }^{10}$.

Porém o mais importante, no assunto, é a defesa que de tal jurisprudencia fizera o principal autor do DIP italiano, Mancini; em trabalho longamente fundamentado ${ }^{11}$ afirmando que o legislador italiano de DIP não quis naquele texto: "farsi arbitro trasformatore e corregitore delle regole de Diritto Internazionale Privato amnesse dagli altri popoli e che ad essi piace mantenere nei propri Stati, cioè sostituirse alla Soveranità naturale ed al Legislatore competente della straniero, per determinare il destino de una sucessione che ornai si riconoscere sottratta all'autorità ed alla competenza dello stesso Legislatore Italiano", e concluindo terminantemente: "Ogni altra interpretazione dell'art. 8 sarebbe manifestamente erronea, eccessiva, ineseguibile. Il Legislatore italiano si arrogherebbe una specie di sovranità mondiale, e si esporrebbe a cadere nel ridicolo si avesse potuto pretendere di imporre a tutti $i$ popoli della terra la sua volontà, e di assoggettarli alle regole di Diritto Internazionale Privato che a lui è piaciuto di scrivere nel suo Codice".

Também Bunntschli na Suiça seguiu diretriz respeitadora do DIP estrangeiro, dispondo no Cód. Civil de Zurique de 1854, em posição reversa às anteriores, que os móveis se regem pela lex rei sitae mas com exceções para "suas relações naturais com diferentes direitos locais e nacionais (art. $4 .^{\circ}$, edic. 1887, art..$^{\circ}$, e Coment. dêle com referência aliás claríssima à "lex domicilii" in Code, trad. de Lehr,

8. H. Valladão, A Devolução, cit., ps. 12.

9. Questioni di Dir. Civ. 1880, II/105 e Introd. al. Dir. Civ. Internaz. e Academia dei Lincei, ps. 15/16, em particular a nota 2 da p. 15.

10. Op. cit., ps. 184 e 232.

11. MancIni, Questione de Diritto, II, 1880, p. 360/7; Recueil Moderne, Meijers ps. 95/100; VALladĀo, Rev. Juríd. (F.N.D.) 11/25, R.T. 204/5; Bolet. Soc. Bras. Dir. Internac. 13/14, p. 34. 
1890, p. 2 nota 1). Era uma aplicação sua de fórmula geral e eqüitativa que ia muito adiante, respeitando o DIP estrangeiro até em matéria pessoal, pois aplicaria ao estado e capacidade, família e sucessões dos estrangeiros residentes em Zurich as leis do seu país, si elas o exigem, Cód. 1854, arts. $2 .^{\circ}$ e $3 .^{\circ}$; de 1887 , arts. $3 .^{\circ}$ (família) e $4 .^{\circ}$ (sucessões). Igualmente, dispuseram os códigos dos Cantões de Zug, 1861 (Bevilaqua, $\S 20$ ), art. $2 .^{\circ}$, e dos Grisões (art. $1 .^{\circ}, 4 .^{\circ}, b$ para as sucessões), e, ainda, para a decretação do divórcio e nulidade de casamento de estrangeiros, a Lei Federal de 1874 prescreveu no art. 54 que era necessário estabelecer que o seu Estado reconheceria o julgamento, texto consolidado no Cód. Civil suíço, art. 59, do Tít. Final.

Na Lei Federal de 25/6/1891 reaparece o princípio em geral para os suiços domiciliados no estrangeiro acêrca do direito das pessoas, família e sucessões, que ficam sujeitos ao DIP. estrangeiro salvo quanto aos imóveis sempre regidos pela lei do Cantão de sua situação, art. $28 \S 10^{\circ}$ (vide, também, arts. 59, $7 b$ e $7 g$ (divórcios de suíços) do Título Final do Código Civil da Suíça) e, ainda, o princípio se consagra especialmente, para o regime de bens do casamento de suiços domiciliados no estrangeiro que será o do Cantão de origem, se o direito estrangeiro não lhes fôr aplicável, art. $31,1 .^{a}$ alínea.

Afinal o princípio do respeito ao DIP estrangeiro do lugar da situação dos bens, foi postulado em forma generica pela EGBGE, L. I. Código Civil alemão, art. 28, seguido pelas leis suecas de $1 / 6 / 1912$, art. $1 .^{\circ}$, de $1 / 3 / 1935$, art. 14 , de $5 / 3 / 1937$, art. $2 .^{\circ}$; na Áustria pelo projeto de 1913 , arts. 22 , 25 (III) e 41 e Decreto de 25/10/1941, art. 16; na Polônia, Lei de 1926 arts. 16 e 19 (3) e 30 (1) ; na Tcheco-Eslováquia, Lei de DIP de 1948 arts. 17 e 23 . O princípio foi aprovado na Alemanha com o nome de o "direito mais próximo", "Näherberechtigung", KAHN ${ }^{12}$, da "maior proximidade", "grösseren Näke", Wolf ${ }^{13}$, da auto-limitação do DIP ale-

12. KAHN, Abhandlungen, I, $\S 9$ e WoLfF, $\S 14$.

13. Op. cit., § 14. 
mão", "Selbsberchränkung des deutschen IPR", por MeLCFrIOR ${ }^{14}$ que o generalizou para aplicar o DIP alemão quando obtenha um certo mínimo de eficácia.

É o grande e básico princípio da efetividade das normas de prr. que vimos defendendo há muitos anos (H. Valladão, Devolução cit. e Rev. Jurídica (Fac. Nac. Dir.) 11 (1952-3), 33 a 36). Nas Convenções de Haia sôbre Tutela de Menores, 1902, art. 6. ${ }^{\circ}$ (2. ${ }^{a}$ alínea) e Efeitos do Casamento 1905, art. $7 .^{\circ}$, e, modernamente, no Tratado Benelux, art. 14 (com menção expressa do DIP. estrangeiro) foi também acolhido aquêle princípio de limitação do DIP do fôro.

Ültimamente, o projeto português do Prof. Ferrer CorrêA, 1951, art. 2. ${ }^{\circ}$ (III) após estabelecer o princípio da nacionalidade para reger o estado, capacidade, família, proclama o reconhecimento da validade dos atos praticados no estrangeiro por um português ali residindo permanente e efetivamente na conformidade das respectivas leis estrangeiras. Eis a renúncia da regra de DIP português em $m a-$ téria pessoal. É ampliação justa de antigo e vigente direito positivo português, art. 24, citado, do Código Civil, aprovado, emendado e bilateralizado por LuCAS FaLCÃo (ps. 192/ 193), justificado pelo Autor do Código (VISconde de Seabra) e pela doutrina como acatamento do DIP estrangeiro ${ }^{15}$.

No Projeto do Prof. Maridakis, do Inst., Droit Int., Ann., 1957, II/53, sôbre a devolução, admitiu êle que em casos especiais, se adote em substituição à regra de DIP (nacionalidade ou domicílio) para familia e sucessões, uma exceção em favor do Direito de outro Estado que seja mais apropriado.

No Brasil, já no Império, Pimenta Bueno estabelecendo o princípio da lei nacional para as sucessões acrescentava "salvo alguma disposição especial do estatuto real", o mesmo fazendo Nabuco no seu Projeto, art. 39. No Con-

14. Op. cit., ps. 398 a 418 , $\S 264$ a 281.

15. Visconde Seabra, Apostila $3 .^{a}$, ps. 18/20, Dias Ferreira, Cod. Civ., I, Comentário, Teixeira DE ABreu, Relac. Civ. Internac., n. 34 . 
gresso Jurídico Nacional de Centenário do Instituto dos Advogados Brasileiros, de 1943, o Ministro Lurz Gallotri propôs em fundamentado relatório e o Congresso aprovou que: "Nos conflitos no espaço de normas de DIP aplica-se se se tratar de conflito positivo, o princípio da renúncia em certos casos. " 15 .

Essa ilustração histórico-comparativa-doutrinária deixa bem clara a manifesta improcedência da afirmativa simplista da absoluta insolubilidade dos conflitos positivos, pois nos mostra fórmulas conciliadoras em leis, convenções e decisões dos tribunais.

$\mathrm{E}$ a tendência geral é a que vimos sustentando desde 1929/1930 (A Devolução. ., Rev. de Direito, v. 96) de se respeitar o DIP estrangeiro, considerando-o e observando-o, quando justo, através a renúncia do DIP do fôro, desde logo em matéria real, quanto a bens, móveis ou imóveis, sitos no estrangeiro e ali sujeitos a norma diversa de DIP.

Eis a solução que apresentamos em nosso Anteprojeto de Lei Geral; "Na observância do direito declarado competente, as disposições dêste não serão aplicadas pelo juiz brasileiro a bens que estão sujeitos pela lei de sua situação, a normas diferentes" (art. 76). Note-se que não limitamos a renúncia do DIP brasileiro, no caso, a um DIP. estrangeiro, que adote a lex rei sitae, mas a um DIP estrangeiro que possua "normas diferentes", p. ex., em matéria de sucessão, que adote a lei da nacionalidade quando no Brasil adotamos a lei do domicílio.

Aliás, justamente, em matéria de sucessões em que Portugal segue o princípio da nacionalidade e o Brasil o princípio domiciliar, a jurisprudência portuguêsa e brasileira chegaram à aplicação, em cada país, dos respectivos principios através da competência judicial dividida, realizando

16. Diário das Sessões, set. 1943, ps. 354, R.T.S.P. 151/20, Rev. For., 99/153, etc. invocando a opinião de ARMinjon, Précis, 1927, 1/152, e a de H. Valladão, Devolução, cit., 52; vide, também Rev. Juŕd. (FND 11/49 e 17/224. 
dois processos autônomos de inventário e partilha dos bens da herança, respectivamente para os bens sitos num e noutro Estado ${ }^{17}$.

Essa extensão do princípio da renúncia do DIP do fôro em favor do DIP estrangeiro mais próximo quanto aos bens, não se restringe, pois, apenas numa concessão à “lex rei sitae" civil, mas a qualquer outro principio de DIP diferente ali seguido, domicílio, nacionalidade, etc...

Ainda em matéria puramente pessoal, estado, capacidade, família, constatamos nos textos de direito positivo antes apresentados várias soluções conciliatórias, em especial nos Códigos da Áustria, Chile, Portugal, México, com limitações ou renúncia do DIP do fôro, restrito aos nacionais ou estrangeiros, domiciliados ou residentes no estrangeiro, aos quais o DIP. do fôro só seria aplicável quanto a atos ou fatos lá praticados que pudessem (Áustria) ou devessem (Portugal, Chile, México) produzir efeitos no fôro; ou na Suiça, Zurich, leis federais 1874 e 1891, e Código Civil, com acatamento geral pelo DIP do fôro das disposições do DIP estrangeiro para os estrangeiros, mesmo no território do fôro, Zurich, e para nulidade do casamento e divórcio, Código Civil suíço, $59,7 \mathrm{~g}$, ou com renúncia do DIP do fôro para os nacionais domiciliados no estrangeiro que ficam sujeitos ao DIP estrangeiro, Lei de 1891, arts. 28 e 31 e Código Civil, Tít. Final, art. 59, letra $h$.

Uma renúncia geral do DIP, do fôro que está em conflito em matéria puramente pessoal com DIP estrangeiro diferente, porém próximo, mais efetivo, por exemplo, em favor do DIP do domicílio ${ }^{18}$ seria perigosa, não havendo como parar no domicílio e não seguir avante, até ao DIP da residência habitual ou até ao da simples residência, ainda mais pró-

17. VALLAdão, Unid. e Pluralid. das Sucessões, Inv. e Partilh. no DIP, opúsculo, 1952, Rev. Juríd. (FND 11/25; R.T.S.P., 204/3; Bolet. Soc. Bras. Dir., Internac, 13/14, p. 34.

18. Assim FeLIX Eckstein, ZAIPR DE RABEL, 8 (1934), p. 140 propõe, levando o problema simplesmente para o campo jurisdicional dando à preferência sempre, tratando-se de pessoal ao Dip do domicílio. 
ximos da pessoa. $\mathrm{E}$, o que é mais grave, muito facilitaria a fraude ao Dip do fôro, às leis da nacionalidade, do domicílio ou da residência habitual, pelos respectivos nacionais, domiciliados ou residentes.

Mais objetiva é a solução do Código da Áustria, melhorada pelos que o seguiram ("devem" em vez de "possam" produzir), limitando o DIP do fôro, quanto às pessoas, aos atos praticados no estrangeiro que produzam efeitos no fôro ${ }^{19}$. Ainda mais justa e eqüitativa é a dos Projetos, citados, de Ferrer Corrêa e Maridakis, reconhecendo, no fôro, plena eficácia aos atos de seus nacionais ou domiciliados, praticados no estrangeiro, ali residindo permanente e efetivamente, de acôrdo com as leis estrangeiras, inclusive de DIP.

Consagramos o princípio em nosso Anteprojeto de lei Geral, ligando-o ao tempo, isto é, através do reconhecimento dos direitos adquiridos, na seguinte fórmula: "São reconhecidos no Brasil direitos adquiridos no estrangeiro, de boa-fé, em virtude de ato ou julgamento ali realizados, de acôrdo com o direito estrangeiro vigorante, salvo se fôr caso de competência exclusiva do direito brasileiro, e observadas sempre as reservas estabelecidas no art. 79".

Destarte o fôro reconhece direitos e situações constituídos no estrangeiro segundo o DIP estrangeiro, salvo se fôr caso de competência exclusiva do direito do fôro, ressalvados sempre atos de má fé ou contrários à ordem pública.

Tais casos de exclusividade do DIP do fôro correspondem, de regra, a um interêsse básico do mesmo fôro, evitando sobretudo a fraude à lei; no Brasil temos um exemplo na Lei de Introdução, art. $7 .^{\circ} \S 6 .^{\circ}$ que não reconhece o divórcio de brasileiro no estrangeiro e, no Anteprojeto da Lei Geral, o art. $66 \S 2 .^{\circ}$.

19. No Brasil, o Trib. de Justiça de São Paulo (O Direito, $101 / 308$ e 309) decidiu, ao tempo em que seguíamos a lei da nacionalidade para os direitos' de família, não aplicar a lei portuguêsa em matéria de filiação natural de pai português, com base no art. 24 do Cód. Port. que só aplica a lei portuguêsa a ato que tenha execução em Portugal. 
5. Apresenta a divergência espacial das normas de DIP um conflito negativo, quando cada qual exclui o seu próprio direito para reger a espécie.

Assim num caso considerado por um juiz brasileiro sòbre direitos de família ou de sucessões de um brasileiro domiciliado em Roma, deveria êle aplicar, segundo o DIP brasileiro (Lei Intr. arts. $7 .^{\circ}$ e $9 .^{\circ}$ ) a lei italiana, do domicílio, enquanto pelo DIP italiano (Cód. Civ., D.L.G., art. 23) seria competente não a lei italiana mas a lei brasileira, da nacionalidade. Se se tratasse de um francês domiciliado na Itália o juiz brasileiro teria de submeter o caso à lei italiana e esta o faria à lei francesa.

A diretriz jurisprudencial quase em todos os paises, inclusive, ùltimamente, a do Estado de Nova York ${ }^{20}$, salvo apenas a da Itália ${ }^{21}$, resolveu o conflito negativo pela teoria chamada da devoluçâo (reenvio, renvoi, rinvio), aceitando $o$ juiz do fôro a referência, a devolução, que a lex causae (a lei por êle declarada competente) faça à mesma lex fori retôrno, (devolução para trás, retôrno, renvoi au premier degré, rinvio indietro, renvoi of remittal, Rüchverweisung), ou a outra lei, para diante, devolução à lei estrangeira (renvoi au deuxième degré, rinvio altrove, renvoi of transmission, Weiterverweisung) ${ }^{22}$. Destarte nessa posição intuitiva, conciliadora entre os textos de DIP divergentes, o Juiz brasileiro aplica a lei brasileira ao brasileiro domiciliado na Itália (retôrno) e a lei francesa ao francês domiciliado na Itália (devolução à lei estrangeira).

O primeiro e espontâneo emprêgo jurisprudencial da devclução ter-se-ia dado, no século xIx, em língua inglêsa,

20. Decisão célebre de 1950, in Harward Law Review, 64/166 e Clunet, 1950, 976/90, sucessão SchNEmER, revogando orientação contrária, no conhecido caso Talmadge; vide também a C. Apelação do Libano, 1951, in ClunET, 1952/926. Para os demais países, inclusive o Brasil, veja-se H. VALLADÃo, A Devolução, cit., ps. $13 / 5$ e os autores constantes da nota 1 .

21. Vide exposição e crítica agudíssima in Philonenko, La $T h$. du Renvoi.

22. H. Valladão, A Devolução, cit., p. 16. 
no caso Collier v. Rivaz, da Prerogative Court of Canterbury, $1841{ }^{23} \mathrm{com}$ a famosa frase de que o juiz do fôro considerar-se-á, para o caso, julgando no estrangeiro ("the court sitting here. . must consider itself sitting in Belgium"); em língua alemã em acórdão de 21 de março de 1861 do Oberappellastionsgericht de LUBECK ${ }^{24}$ com a incisiva declaração: "a exata observância do princípio de direito comum (de DIP do domicílio para as sucessões) exige que a legislação em vigor no domicílio do de cujus seja aplicada em sua totalidade", inclusive, pois, quando devolve ao da nacionalidade; finalmente em língua francesa no célebre caso Forgo ${ }^{25}$ em julgados da Côrte de Cassação da França, 1878 e 1882 (relator, o ilustre especialista, DemanGEAT, anotador de FoELIX), submetendo a sucessão dêsse bavaro à sua lei nacional mas aplicando afinal a lei francesa, dos respectivos domicílio e situação dos bens que a lei bavara de DIP (en matière de statut personnel ou réel) indicava para a espécie ${ }^{25}$.

Essa jurisprudência, pràticamente universal ${ }^{27} \mathrm{em}$ prol da devolução, teve magnifica consagração legislativa.

Foi adotada na maioria absoluta dos textos internos vigentes no Mundo desde a Suíça, Cantões de Zurich

23. In LoRENZEN, Cases, ps. 827/8. Essa frase levou a jurisprudência, por vêzes, ao chamado "double or total renvoi theory", in re Annesley, in re Askew, in re Ross, in re Duke of Wellington (WolfF, 195/196, Graveson, 464/69, etc.) aplicando, naturalmente, o DIP estrangeiro na sua totalidade, inclusive nos seus textos sôbre a devolução. Vejam-se os magistrais trabalhos de DE Nova a respeito, in Rivista, 1938/388-426 e Giurisprud. Comp., XI/120. Também H. VALLADÃo, Estudos, p. 133.

24. Apud LEWALD, Recueil, 29/535/6.

25. ClUNET, $1897 / 285$ e 1883/64; citado e comentado por todos os autores foi objeto de um estudo, em profundidade, por PHILONENKo in ClunET, 1932, ps. 281 e ss., especialmente, ps. 297/8 e 321/2.

26. Decisões anteriores ao Século XIX, na França e outros países encontram-se reunidas em Deraume G., Conflits de Lois à la veille du Code Civil, e em artigo de NrBOYET, Revue, 1926, ps. e ss., com a admissão "pour Froland" de um caso de devolução.

27. Autores citados na nota 1. 
(Bluntschli, 1854-55, arts. $2 .^{\circ}$ e $\left.3 .^{\circ}\right)$, de Zug (1861, art. $2 .^{\circ}$ ), Leis Federais, de 1874, art. 56, de 1891, art. 28 (2) e 31 (1) e Código Civil, art. 59 ( $7 f$ e $g$ ); a Hungria, na lei sôbre o casamento, art. 108; a Alemanha, na EGBGB, art. 27; o Japão, na lei de 1898, art. 29; a Suécia, Lei de 1904, art. 2. ${ }^{\circ}$; a China, Lei de 1918, art. $4 .^{\circ}$; Palestina, Order in Council 1922, art. 64 (2) e sôbre Sucessões, art. $4^{\circ}$ (III) ; a Polônia, Lei de 1926, art. 38; Liechtenstein, Lei de 20/1/1926 (pessoas e Sociedades), art. 70 da Parte Final; Finlândia, Decreto $5 / 12 / 1929$, art. 53; Lei soviética sôbre o cheque, 1929, art. 36; Letònia, Código Civil, 1937, art. 23; Sião, Lei de DIP de 1939, art. 4. ${ }^{\circ}$; Cód. Civil Romeno, de 1939 (não vigente), art. $24 .^{\circ}$; Áustria, Decreto 25/10/1941, Familia, \& 15; Iugoslávia, Lei de 23/4/1955, Sucessões, art. 156; Lei da Coréia do Sul, n. 966 de 15/1/1962, de Direito Extranacional ou de Conflitos, art. 4..$^{\circ}$; Lei da Tcheco-Eslováquia, de 16/12/1963, art. 35 (se a devolução leva a uma solução razoável e equitável). Enfim a devolução é aceita nas Repúblicas Democráticas Populares a partir da Rússia (LunTz, IPR., trad. alemã, 1961, págs. 232 e ss.), segundo é, ainda, confirmado em estudo recente do eminente professor húngaro, Izaszy, E., na Revue, artigo 1963-244-6. A condenação do reenvio na Itália, em 1939 (em divergência com o projeto, sendo sua jurisprudência absoluta, ùnica no mundo em tal sentido), D.L.G., art. 30, ali criticada por Balladore Palieri e outros eminentes especialistas - constituíu uma exceção nos textos vigentes no mundo, que influenciou apenas o Código da Grécia, de 1940, art. 32, a lei brasileira (Decreto-Lei da ditadura, vi, clam et precario de 1942, art. 16) e os Códigos do Egito de 1948, art. 27 e da Síria, 1949, art. $29^{28}$.

A fórmula italiana não repercutiu em outros países, sequer nos projetos posteriores. Em verdade, a favor $d a d e-$ volução são os mais recentes Projetos de DIP; Venezuela,

28. H. Valladão, A Devolução, cit., Lei Geral, ps. 117. No Apêndice à obra de Franceskakis, cita êstes textos de vinte países sôbre a devolução, dos quais 15 a favor e apenas 5 contrários. 
1963, art. $4 .^{\circ}$; Polônia, 1961, art. $4 .^{\circ}$; Portugal, 1951, art. 30, da França, 1950, art. 20, e, mais antigo, o Projeto Áustríaco, de 1913, art. 53, aceitando, claramente, o retôrno e a devolução à lei estrangeira ${ }^{29}$.

Nos atos internacionais, consagrada a devolução desde a Convenção de Haia de 1902 , sôbre casamento, art. $1 .^{\circ}$, foi mantida, posteriormente, nas Convenções de Genebra de 1930 e de 1931 sôbre Conflitos de Leis na Cambial (art. 2. ${ }^{\circ}$ ) e no cheque (art. $2^{\circ}$ ), e ùltimamente, de forma básica na Convenção de Haia de 15/6/1955 para regular os conflitos entre a Lei Nacional e a do Domicílio, art. $1 .^{\circ}$ aceita até pela Inglaterra, e, ainda, em grande parte, no Projeto Benelux, arts. 15, ns. 2 e 3 (Sucessões, devolução à lex fori e à lei estrangeira) e 25 (a propósito do direito adquirido), sendo que as três primeiras Convenções vigoram na própria Itália, e na mesma Grécia. ${ }^{29 \mathrm{~A}}$.

6. Entretanto aquela corrente doutrinária "apriorista", irrealista, do absolutismo e do universalismo da lex fori de DIP, já apontada e criticada a propósito do conflito positivo (antes, n. 3), combateu apaixonada e às vêzes, violentamente, em "nome da ciência", para evitar "o desaparecimento de DIP", a aceitação jurisprudencial e legislativa da devolução, predominando nos fins do Século xix e princípios do atual, conseguindo apoio frouxo do Institut de Droit Internationale, em resolução que a considerava "não

29. O projeto húngaro, primitivo, art. 11, também adotava a devolução, e só recuou, art. 11 do novo por ter a jurisprudência ali mudado, qual aconteceu na Itália com recuo idêntico do texto do Projeto para o vigente. Segundo informou o eminente BABINSKy na reunião de Varsóvia do Inst. Dr. Int. o projeto polonês já foi aprovado nas Comissões do Congresso e será breve lei. O novo projeto português (1964) mantém o reenvio em casos especiais, art. $4 .^{\circ}$.

29A. Aliás nas convenções internacionais a devolução é a fórmula ideal; considere-se a defesa que dela fêz, agudamente, M. CAPITANT (Traités des Dr. Privés..., 1928, 152 e ss.). 
desejável nas leis internas" na Sessão de Neuchâtel $1900{ }^{30}$. Exemplo do calor dessa reação "logicista" contra o bom senso e a eqüidade das decisões e das leis são, na França, aquelas e outras duras expressões de LABBÉ, LAINÉ ("funeste", "resultat d'une méprise"), Bartin, Pillet ${ }^{31}$ e a resposta firme do Conselheiro Denis na Côrte de Cassação, "j'aime mieux ce qui est simple que se qui est embrouillé" 32 .

Mas iria prevalecer, depois, opinião ponderada, objetiva, conciliatória, aceitando a devolução sem absolutismo, de grandes mestres de DIP., de um Asser na Holanda, de um von bar na Alemanha, de um Westlake e de um Dicey na Inglaterra, de um Weiss e de um de VareIlles-Sommières na França, de um Rolin na Bélgica, de um Brocher (1881 I, n. 55, p. 167) e de um Roguin na Suíça, de um Fione e de um Brusa na Itália, de um Torres Campos de Granada, Trias y Giró de Barcelona e Conde y Luque de Madri na Espanha, de um Walker na Áustria, de um Clovis BevilaQUA no Brasil. Assim após o primeiro quartel do nosso século com outros especialistas, Frankenstein ${ }^{33}$, Ennecerus (1926, n. 60), Nussbaum (1932, § 12), Melchior (1933, Regel I, $\S \S 133-43)$, Wolf $(1933, \S 13$, n. IV), RaApe (Recueil, 1938, 50/410), Lewald (Règles Générales, 1941, p. 60, restritamente "como expediente útil em situações especiais") na Alemanha; Lerebours-Pigeonnière (1927, p. 240-3, antes, Clunet, 1924/877), Donnedieu des Vabres, H. (Dr. Pen. Int., 1928,

30. Ann., abregé, 1928, ps. 505, 506 a 512 (defesa do "renvoi" por WestlaAKe) 531 a 560 (discussão) e 561 (votação, 21 contra 6, nestes, especialistas eminentes quais voN BAR, BRUSA, Roguin, Weiss e WeStlake, naqueles predominando os publicistas, contando-se entre os especialistas ASSER em posição transacional, 545/6, BUZZATI; CATELLANI, STREIT).

31. H. Valladão, A Devolução, ps. $18 / 19$ e respectivamente in Clunet, 1885/10; Clunet, 1896/241 fine e 253 e Revue, 1906 a 1909; Clunet, 1897/737; na obra Principes, $\S \S 63$ a 66 . Inspirado nesses exaltados doutrinadores Machado Villela (Trat. I, ps. 514 e ss., e, especialmente, (DIP. no Código Civil Bras., ps. 348).

32. Clunet, 1912/1009 a 1013 .

33. H. Valladão, A Devolução, cit., ps. 20/21. 
p. 388), J. Maury (1936 Recueil, 57/549-50), Donnedieu DES VABRES, J. (L'Évolut., 1938, p. 728: "un peu de science eloigne du renvoi. . beaucoup y ramene") na França; ANziLotri (1925, Corso di Dip, 51 e ss., 76/78, antes nota in Rivista, 1918, p. 289, mudando aí anterior opinião contrária in Corso di Lez. di DIP - Dir. Priv. de 1913, litografado em Roma 1919, ps. 102/105 e antes Studi Grit., p. 193, n. 1) e FEDozzi (1935, DIP, ps. 214/218 aprovando o Projeto italiano favorável ao reenvio) na Itália; Poullet (1925, p. 280) na Bélgica, Sanchez de Bustamante (1927, Proj. Cod. Dip, art. 7. ${ }^{\circ}$ na América Latina, Tris de Bes (1930, Recueil 31/663) e W. Goldschmith, La Conseq. Jurid. de la norma del DIP n. 8) na Espanha, Schnitzer (1937, Cap. VIII) na Suiça, Benrwrrch (1934, Recueil 49/58 e livro Domicile, Sucess. and Renvoi, 1912) na Inglaterra, Griswold (1937, 51 Harvard L. Rev., 1181/2) e Cowan (1938, 87 Univ. Pensilv. L. Review, 34) nos Estados Unidos, Johnson, W. (1937, III, 93-4) no Canadá, Eduardo Espinola $(1925, \S 42)$ no Brasil 34 , E. Ballogh (1936, Recueil 57/621 e ss.) e S. Bundstein (1936, Revue de Dr. Int. et L. Comparé, de Gand, 1936/527) no direito comparado.

Destarte o Institut de Droit International também evoluíu, alterando a diretriz de Neuchâtel 1900, para adotar na Sessão de Oslo, 1932, o "reenvio feito pela lei nacional a outra lei", em matéria de "capacidade", "considerando que após esta época (1900) uma corrente de ordem convencional, legislativa e jurisprudencial manifestou-se em diversos países a favor de certas aplicações desta doutrina (devolução) ${ }^{35}$.

No após guerra avoluma-se aquela corrente doutrinária, equilibrada, a favor da devolução, na França com a conversão de Niboyet (Cours, 1947, n. 498, já iniciada no Traité, vol. III, 1944, p. 483; antes "rejeitava-a absolutamente",

34. A tal corrente aderimos desde nossa tese de docência livre, A Devolução, cit., 1929/1930, também Rev. de Direito, v. 96.

35. Ann. 1932, vol. 37, ps. 566/7. 
Manuel, 1928, p. 491), seguindo-se Lepaulle, P. (1947, p. 174, Clunet, 1936, p. 290), Batiffol (1949, ns. 305 e ss.) e, agora Franceskakis ( $O p$. cit., que combatendo o "renvoi" admite-o, expressamente, em três largos casos, da lei nacional para a do domicílio pois estão hierarquizados na França, de exclusão do DIP do fôro para situações adquiridas no estrangeiro e para manutenção da validade de um ato (ps. 261/2), convertido também, Louis Lucas (1964, Revue, ps. 4/5; antes contra, Repertoire, 10/427; e, ainda, Maury (Ann. Institut D. I., 1957, ps. 77/8) ; na Alemanha, RAAPE (1950, § 10), Pagensticher, M. 1951, Der Grunsatz., cit., p. 68); Makarov (Ann. Institut, 1957, II, p. 75), Wengler, Recueil, 104/375 e Ann. Institut, 1957, p. 105/6), Lewald (1950, a propósito do caso Schneider, de N. York, ampliando suas próprias exceções), e finalmente, o mais recente tratadista, o Prof. KEGEL G., IPR (1960 que declara incisivamente: "Nur ver genau so entschetdst, wie ein Ausland tatsälicht entschieden wird, macht jedoch vollen Ernst mit der Anvendung auslandischen Rechts"); na Inglaterra, Graveson (em parte, 1948, p. 57 e até hoje, 1961, p. 70), W. Raeburn (1948, The open ofer formula, 1948, B.Y.B.I.L. 211), WolfF (1950, Chap. XV), Schmitoff (1954, ps. 95 e 101/102); no Canadá, Falconbridge (1947, p. 158, abrandando anterior condenação radical, para admitir em certos casos); nos Estados Unidos com RaApE (1945, I, p. 70 e ss., antes in Rev. Der. Priv., Madri, 1931/367), Marsh Harold (1952, Marit. Property in Confl. of L., p. 114 apud Verplaetse, p. 283, n. 10), Briggs (1953, Vanderbilt L., Rev., em parte) e von Mehren, A. T., 1961 (Yntema, Essays 394); na Espanha, Gestoso Tudela (1947, La Teoria de la Referencia en DIP), ORuÉ (1952, n. 326, (1952, I, p. 354), AgUILAR Navarro M. (1955, p. 404, antes Rev. Esp. D. I., 1950/813), Verplaetse, J. G., (1954, p. 283) ; em Portugal, com novos professôres titulares, que aceitam a devolução Ferrer CorRÊA (Proj. português, art. 30 e DIP, Lições aditamento, 1954, ps. 52 e ss.) de Coimbra, e Isabel M. T. DE Magalhães 
Collaço, A Devolução, Coimbra, 1959, parcialmente ${ }^{36}$, de Lisboa. Na Suiça o emérito especialista SAuser-Hall (1959, Ann. Institut, II/40, oração inaugural como Presidente), Niederer (1961, Ann Institut D. I., 1961, 293/4) e ainda JAGMETtI (Revue 1961/615); na Holanda, MeIJERs (1951, Proj. Benelux, art. 25), Offerhauss e Kirsch (1959, Ann. Institut, p. 285/6 e 291); na Itália, QUADrI (Lezzioni, 1958, ps. 331 e 334, Ann. Institut, 1961, p. 309), Balladore Palieri (1959, n. 36), Monaco (Efficacia, 1952/68 citando, ainda, Ziccardi), De Nova (1961 Ann. Institut, p. 312); no Chile, Dinker Biggs (Dip, 1950, n. ${ }^{\circ} 414$ ).

Não pôde, assim, o Instituto de Direito Internacional em sua Sessão de Strasburgo, 1961, aprovar o Relatório e conclusão, contrários à devolução, do eminente Professor Georges Maridakis, de Atenas, Ann. 1957, I, ps. 1/17, apesar de conter uma exceção. Na comissão e plenário manifestaram-se adversamente, eminentes professôres, em geral ou com reservas; assim Trias de Bes, Makarov, Maury, Batif-

36. A ilustre catedrática considera a condenação total da devolução pelos Códigos italiano e grego produto de "aquêles sistemas mais intolerantes" de DIP; fiat justicia pereat mundus" (n. 65, p. 53). Mantêm êsses juristas tradição que vem do eminente VEIGA BETRÃo (in Clunet, 1908/367-375), já seguida pelo Dr. Luzo SOARES. A teoria da Devolução e a consideração da lei estrangeira, Lisboa, 1950). Quanto à jurisprudência está assente a favor da devolução, segundo declarou o próprio Supremo Tribunal de Justiça, com invocação do art. 240 do Estatuto Judiciário que a manda observar, no acórdão de 23/1/1959 (caso Hargreaves) in Bolet. Min. Just. 83, com referência especial ao ac. de 14/12/1936 (caso Levy), Rev. Tribs. 55/23, e a outros procedentes judiciais, p. ex., aca. de 28/10/1952 (caso Allard) Rev. Legisl. e Jurispr. 85/268, de 15/12/1950, Boletim 22/343; o primeiro caso foi a decisão do Juiz SoARes de Albergaria (caso Davidson) publicado na Rev. Leg. e Jurispr. 40/335 e no Clunet, 1908/369. O Doutor VASCO TABORDA FERREIRA em parecer dado à Fund. Calouste Gulbenkian analisou a jurisprudência citada até 1958, concluindo que ela não acolheu a devolução. Mas após, em 1959, concluíu, contràriamente à interpretação do ilustrado jurista; manteve a aceitação da devolução e com caráter de norma a seguir pelos tribunais. "No Brasil diríamos que o Tribunal o incluíu na "Súmula". 
fol, Wengler, Babinsti, Wortley, Balladore Palieri, Kirsch, Eustathides, Spiropoulos, Niederer, Offerhauss de Nova. Eu também na Comissão e no plenário combati os têrmos gerais da proposta, e, afinal, propus com Batiffol, Makarov, De Nova, Trias de Bes, Egawa e Van Hecke voltasse o assunto à Comissão para reestudo, o que foi aprovado (Ann. 1961, v. 49 , II, págs. 279 e ss. e 318 e ss.).

7. No Brasil, ao contrário do ocorrido em outros países, a doutrina se firmou, desde logo, a favor da devolução, antes que a jurisprudência a consagrasse.

Assim, para citar apenas os grandes mestres, o "primus inter pares", Clovis Bevilaqua ( $\S 20$, da 1. a , 1906, à última edição, 1944 e Código Civil comentado, art. 8. ) ; Lafayetre Pereira (Pareceres, I, n. ${ }^{\circ} 124$ (1902), sucessão no Brasil de norte-americano, domiciliado na Inglaterra, a lei brasileira, do estatuto pessoal (nacionalidade) remetendo, afinal, $\dot{a}$ lei inglêsa (do domicílio) e no seu Projeto de Código Pan-Americano de oIP nos Estados do Leste europeu, além de LunTz, na Russia, Filispecu, na Rumânia (Drept I.P. 1964, págs. 78/ 79) L. RÉczeI, na Hungria (DIP em hungaro, $3 .^{\circ}$, 1961) Bystricky, R., na Tchecoslováquia (DIP em tcheco, 1958). (1909, art. 119), Eduardo Espinola (Sistema, I, 1908, p. 203, Anot. ao Cód. Civil Brasileiro, v. 2., 1922 , ps. 210 e ss., Elementos, 1925, \& 42 e com Espinola Filho, Trat., 1941, vol. 7, n. 93 ps. 620/1, L. Introd., III, 1947, p. 489), Didimo DA Veiga (Congresso Juridico de 1908), Edmundo Lins (Aulas in Rev. Forense, XVI/19 e Acórdão no Supremo Tribunal Federal in Arq. Judic. II (1927) p. 48); Bento de Faria (Aplicação e Retroatividade da Lei, 1934, n. ${ }^{\circ} 80$, p. 169); F. Morato (Rev. Trib. São Paulo, 81/16; Laudo de Camargo (em São Paulo, R.T., 83/122 e no Supremo Tribunal Federal, acórdãos) ${ }^{37}$.

37. No mesmo sentido Numa do VAlle, Família no DiP, 19, 284, Pontes de Miranda, Trat. Testam., 1), n. 181. Opinião dissidente, singular, era, apenas a do professor OSCAR TENóRIo em termos radicais sob influência da antiga e estremada doutrina francesa, (1942, até 
A jurisprudência brasileira, segundo salientamos desde $1930^{38}$, completando nossa informação em estudos posteriores até o presente ${ }^{39}$, tornou-se assente, em numerosos julgados, a favor da devolução, interpretando nesse sentido as normas de DIP brasileiro (Intr. Cód. Civil), omissas a respeito.

Assim após 1929/1930, os acórdãos do Tribunal de Apelação de São Paulo, de 4/6/1931 e 25/5/1932 (LAudo DE CAMARGo) in Rev. T.S.P. 81/125 e 123, de 14/12/1938 (THEODomrro Dras, longamente fundamentado, mostrando que: "Longe de encerrar atentado contra a soberania nacional, a adoção do princípio do retôrno ou devolução dignifica homenagem a essa soberania. " R.T.S.P., 118/716) e de 28/3/1940 (PAulo Colombo, afirmando ser "a jurisprudência sempre pela aceitação do retôrno" e citando acs. de $22 / 3 / 27$ (Rev. Tribs. 61/500), de 21/8/28 (R. T., 69/117), de 4/6/31 e 25/5/32 já citados, de 6/4/32 (R. T. 84/185).

Para o Supremo Tribunal Federal ,citem-se os acórdãos de 5/11/1937, apel. civ. 6832, Eduardo Espínola dizendo ser neste sentido a jurisprudência da Côrte e citando a declaração de Melchror, G., de que a jurisprudência brasileira aceita a devolução, in R.T.S.P., 112/134 e Arq. Judic. 47/16; de 27/12/1937, apel. civ. 6716 (Plinio Casado, de acôrdo com parecer de Luiz Callotti, in Rev. For. 72/40, in Rev. For. 74/457) e, finalmente, o de 28/12/1937 na apel. civ., 6742 (Eduardo Espinola, com citação de sua opinião doutrinária (favorável) in Arq. Judic. 47/248).

8. Entretanto, a Lei Introdução de 4/9/1942, promulgada pela ditadura, "vi, clam et precario" (vide Capít. anterior,.$^{\circ} \mathrm{XV}$ ), tentou proibir a devolução no art. 16 , que é uma tradução, ipsis litteris, do art. 30 da D.L.G. do Cód. Civ. italiano, 1939-1942.

hoje mantida, I, 1960, 516/7); ùltimamente, porém, no mesmo sentido, de forma apaixonada, sob inspiração das idéias de LewaLd e Perroud, o professor AMILCAR DE CASTRo, de Belo-Horizonte (I, 1956/277).

38. H. Valladão, $A$ Devolução, ps. 88.

39. H. Valiladão, Estudos, ps. $132 / 135,182,460 / 451$. 
Compreende-se que o Cód. da Itália condenasse a devolução, não aceita pela maioria da doutrina e pela jurisprudência assente da península, embora o texto tenha sido ali criticado pelo seu caráter "sbrigativo" (Balladore PALIERI, cit., p. 111) e interpretado restritivamente (MoNACO, Eficaccia, p. 69) e, recentìssimamente, o próprio AGo in Riv. 1963, e acórdão do Tribunal de Turim aplicando, ampliativamente, a Convenção da Haia de 1902 para admitir a devolução na Itália apesar do texto proibitivo daquele art. 30 (Riv. 1962/618). E, por isto mesmo, não se compreende como o legislador brasileiro (só mesmo a ditadura de 19371945) copiasse aquêle texto italiano radicalmente contrário à doutrina e à assente jurisprudência brasileira.

Daí a crítica que lhe fêz logo o eminente e saudoso professor Serpa Lopes ( $L$. Intr. III, p. 392: “a questão não podia ter sido riscada pela forma radical exarada no art. 16", "Essa tradução literal. não obedeceu a um prévio e cuidadoso exame científico da matéria". A reação fôra mais longe pois os juristas brasileiros condenaram o citado art. 16 na Comissão de dip (presidida por Edvardo Espinola) do Congresso Jurídico Nacional de 1943 (Diário das Sessões (setembro de 1943), págs. 354; Rev. Jur. (Fac. Nac. Dir.). 17/224-226; R.T. S. Paulo, 151-20, Rev. Dir. 148-44, Paraná Judiciário, 39-422, Rev. For., 99-563, aprovando o fundamentado relatório do eminente Ministro Lurz Gallotri, que concluíu: "Nos conflitos no espaço de normas do DIP, aplica-se, se se tratar de conflito negativo, a devolução, ainda quando se verifique para outra lei que não a "lex fori”. Ainda, ùltimamente, o Professor Adauto Fernandes, catedrático da Fac. de Direito da Univ. Fluminense, defende, doutrinàriamente, a devolução, e crítica, fortemente, o art. 16 da Lei de Introdução (Elementos de DIP., p. 164 e 167).

A essa reação doutrinária tem correspondido uma jurisprudencial pois os Tribunais brasileiros continuam em diversos casos a aplicar a devolução. 
Começou por um dos próprios autores da L. Introd., o Ministro Philadel.PHo Azevedo ${ }^{40}$ que para aplicar, segundo o DIP brasileiro, a lei nacional dum argentino, declarou que "segundo ela, regeria o princípio domiciliar", no caso a lei uruguaia por ter o argentino fixado "domicílio no Uruguai" (é a devolução a terceira lei, à lei estrangeira, lei brasileira para argentina e esta para a uruguaia). Assim o Tribunal de Justiça de São Paulo, em acórdão de 8 de março de 1960 (R.T.S.P. 304/216), e até o Supremo Tribunal Federal nos Recs. Extra. 31.655, 1. ${ }^{\text {a }}$ Turma, ac. de 24-1-1957 (Min. CÂndido Mota Filho, Rev. Trim. Sup. Trib. Fed., 1/605) e 34.273, 2. ${ }^{a}$ Turma, ac. 21-10-1958 (Min. Villas-BoAs / D. J. 28-1-1959, Ementa).

9. Por tudo isto, levando em conta o direito pátrio, sua contínua tradição jurisprudencial e doutrinária através de suas manifestações supremas antes mencionadas, e o direito mundial, doutrina predominante, jurisprudência assente e a quase totalidade dos textos legislativos e projetados, o Ante-projeto de Lei Geral, brasileiro, aceitou a devolução no art. 77 que assim dispõe: "Na observância do direito estrangeiro declarado competente, o juiz brasileiro atenderá às disposições do mesmo direito sôbre a respectiva aplicação, inclusive a referência a outro direito com base em critério diferente, religião, raça, origem, naturalidade, nacionalidade, domicílio, vizinhança, residência, território etc." ${ }^{41}$.

O preceito resolve o conflito negativo de normas de DIP., com regra ampla que orienta o juiz brasileiro na aplicação, em geral, do direito estrangeiro declarado competente, inclusive na referência que êle faça, o que ocorre, freqüentemente, a critérios diferentes, p. ex., à religião, à raça, à origem, à nacionalidade, à naturalidade etc..

40. H. Valladão, Estudos, ps. 133 e 182; voto na Sentença Estrangeira 1028 (D. Just., 18-8-1943, p. 5479 e de 5-10-1943, p. 3960).

41. O parágrafo único contém limitações nestes têrmos: "A referência acima só ficará excluída se não fôr feita ao direito brasileiro ou se não fôr feita a qualquer outro direito que afinal a aceite". 
O principio fundamental do texto é o de que na observância do direito estrangeiro o juiz brasileiro não procederá irrefletidamente, atenderá às disposições do mesmo direito sôbre a respectiva aplicação, vigência espacial, pessoal e temporal, interpretação, etc.. Evidentemente seria inadmissivel que o juiz do fôro, no caso, o juiz brasileiro, fôsse decidir sôbre a data e o lugar em que vigora uma norma estrangeira, sôbre sua interpretação, etc., levando em consideração os princípios sôbre a aplicação das leis no Brasil.

Mas se a lei estrangeira, qual ocorre em vários países, determina a regência da espécie por um critério diverso, para aplicar uma lei religiosa (em numerosos países do Oriente e mesmo do Ocidente, Portugal, Itália, Espanha, etc.) ou uma lei do grupo étnico (Tcheco-Eslováquia, Lei de DIP., art. 54, fine) ou uma lei racial ou tribal (numerosos países da Ásia e da África, inclusive nas Províncias portuguêsas de Ultramar) ou uma lei de origem (Suíça), ou da naturalidade ("ciudadania local o de natividad", p. ex., México, H. Valladão, Estudos, págs. 52), ou da "vizinhança" (Espanha), domicílio, residência, nacionalidade, território, zona etc. - tal referência deverá ser aplicada.

$O$ texto resolve dois problemas que alguns separam sem razão, e que sempre reunimos (ainda modernamente os une, também, Ba'riffol, pág. 305) pois se a lei brasileira de DIP, manda aplicar a lei do domicílio para reger o casamento e o domicílio dos interessados é em Portugal e o direito português, na metrópole, manda aplicar, se são católicos, o direito da Igreja Católica, ou, no Ultramar, o direito da respectiva tribo - o juiz brasileiro há de aplicar aquêle direito religioso ou tribal, como também aplicará, p. ex., a lei brasileira ou outra lei estrangeira nos casos em que a lei portuguêsa de DIP ordenar a aplicação da lei nacional.

Fora daí é deixar o caso sem solução, verdadeira denegação de justiça ou desnaturar, ditatorialmente, as leis estrangeiras, de voltar atrás após ter prescrito a sua apli- 
cação... E, no dizer sempre conciso e perfeito de CLóvis Bevilaqua, é "amputar a lei estrangeira que a lei pátria mandou aplicar (Op. cit., 4. ${ }^{\mathrm{a}}$ ed., 1944, p. 146).

10. No Anteprojeto, art. 77, consubstanciamos nosso modo de ver, de seguir as referências que o direito estrangeiro, declarado competente, faça a outras leis, expresso em numerosos trabalhos nossos no Brasil e no estrangeiro desde 1929/30 ${ }^{42}$.

A nossa orientação tem sido a de não seguir pontos de vista extremados, e, sobretudo, apaixonados num assunto que há de ser solucionado não com rigorosos princípios de lógica formal mas atendendo a razões de justiça, eqüidade e conveniência no ideal humano de solidariedade jurídica universal, antevisto por SAvignY, da comunidade jurídica entre os povos.

Se a lei do fôro ordena ao seu juiz que aplique, em certo caso, outra lei, seja de uma outra nação ou a de um outro Estado, ou mesmo, internamente, de um para outro (a) Código ou lei, é para que êle a cumpra integralmente e não o fará se a considerar apenas numa parte, p. ex., em um artigo sôbre sucessões, ali pinçado violentamente, abstraindo dos outros textos que lhe dão vitalidade, condicionando-o no tempo (vigência, retroatividade ou não), no espaço (território, regras de DIP), na interpretação, etc...

E essa a diretriz normal e justa, que atende à finalidade da ordem e à justiça para o caso, acatando e respeitando a outra lei que se julgou mais apta a decidí-lo.

Afastando-se, não considerando a outra lei em seu todo, o juiz do fôro altera-a, modifica- $a$, cria êle próprio "uma terceira lei" que não é mais a "outra lei" pois cada legis-

42. H. VAlladão, A Devolução cit., .... e Rev. Dir., v. 96; Estudos, 1948, 132, 181 e 460/I, Delta Larousse, Dip., n. ${ }^{\circ}$ VIII; $A$ Lei de Intr. ao Códig Civil in Rev. Jur. (Fac. Nac. Dir.) 17-219; Ann. de l'Inst., 1957, v. 47, II, págs. $89 / 92$ e 1961, v. 49, II, págs. 316/318). 
lação, cada direito, é um sistema, vivendo cada texto, cada lei, em função de outros, genéricos ou especificos que o delimitam substancial, temporal e espacialmente.

Ademais a referência, a devolução, a outra lei, é a vocaçâo própria da norma de DIP., e, pois, o juiz do fôro indo à lei estrangeira em cumprimento à lei do fôro, deverá acatar a referência que ela faça, também, a outra lei. E raciocínio normal, em desenvolvimento espontâneo da norma inicial do fôro para que seja atingida a respectiva finalidade.

Proibí-la e, absolutamente, qual fêz o art. 16 da L. Intr. levará, ainda, às mais bradantes injustiças ${ }^{43}$, como se poderá ver nos exemplos seguintes: cumprindo aquêle art. 16, o juiz brasileiro para apreciar a validade substancial de um casamento de pessoas domiciliadas em Portugal, na Metrópole ou no ultra-mar, deverá aplicar a lei do domicílio (art. 7.a L. I.), a lei de Portugal "sem considerar qualquer remissão por esta feita a outra lei", e, assim, apenas os arts. sôbre casamento do Código Civil de Portugal, embora o direito português mandasse aplicar, para a espécie, e tivesse mesmo sido aplicado, o direito canônico se católicos, o direito tribal se indígenas, o direito brasileiro se brasileiros ${ }^{44}$.

Os argumentos contrários à devolução, enunciados, emocionalmente, nos fins do Século XIX e repetidos na Europa até a década dos trinta, no Brasil ainda agora, já estão ultrapassados, qual se pode ver de qualquer artigo ou livro atualizado.

43. Com acêrto Verplatetse pergunta referindo-se ao art. 30 dos D.L.G. do código italiano e aos que o copiaram se "these provisions are not the Procustean bed of justice" (Revue Hellenique, 1955, p. 157).

44. O insigne e saudoso Professor RABEL imaginando também um caso de devolução irrecusável chegou a dizer que "The unsound rejection of renvoi in article 16 were relaxed to permit further reference from Cuban to German Law", que "a errônea regeição do reenvio pelo artigo 16 se afrouxava para permitir referência posterior da lei cubana à lei alemã" (IV, p. 518). 
As objeções contrárias à devolução têm uma característica comum: consideram o problema em abstrato, no vácuo, fora da terra, e num logicismo formal já inadmissível no campo jurídico ${ }^{45}$.

Assim é irreal dizer que o juiz do fôro seguindo a devolução - a remissão - estabelecida pela lei estrangeira, arria a bandeira da soberania nacional frente à estrangeira, pois o juiz do fôro está, simplesmente cumprindo a regra do fôro que o mandou aplicar a lei estrangeira, e tanto não abdica êle da soberania nacional ao aplicar a lei sucessória estrangeira quanto ao aplicar a lei da remissão estrangeira, e muito menos o que seria paradoxal, ofenderia o juiz brasileiro à soberania brasileira se tendo que aplicar a lei do domicílio para a sucessão dum brasileiro domiciliado em Portugal, aceitasse a devolução do direito português e aplicasse a lei nacional, no caso a lei brasileira.

Assim as distinções que se pretende fazer na expressão "lei estrangeira", usada pela regra de DIP do fôro, para limitá-la às leis estrangeiras "internas" e não às "leis estrangeiras internacionais" que seriam as de DIP, estrangeiro são imaginärias, não correspondem ao direito vivo, positivo, pois, não só em sua absoluta maioria as regras de DIP são "internas", como o juiz de um país, nacional ou estrangeiro, ao resolver em concreto uma questão, p. ex., de sucessões, não aplica exclusivamente o artigo de sua lei sucessória mas todos que c delimitam, alterando-o, revogando-o, restringindo-o, temporal ou espacialmente, etc. ${ }^{46}$.

Assim, também, só no vácuo, fora de tempo e espaço, se verificará o chamado "circulus inextricabilis", o gabinete de espelhos, de o DIP do fôro remeter ao de outro Estado

45. Exposição e crítica in H. Valuadão, A Devolução e Rev. Dir., vol. 96, e nos autores modernos, já citados.

46. As distinções, "civil”, "comercial". "penal", "processual”, são puramente acadêmicos. O direito positivo, aplicado pelos tribunais é um todo, um sistema. 
e êste ao primeiro, e, assim, infinitamente, pois, no caso concreto, um juiz de determinado país está apreciando certa espécie em certo local e tempo e sua lei o remete para decisão do caso à lei doutro país, e esta lei dará a solução definitiva, pois tem o domínio do caso ${ }^{47}$. Não se trata de ficar no ar, comparando, de cima, fora da vida, as duas leis divergentes de DIP. Constitui o argumento num êrro de posição, já usado pelos sofistas gregos ${ }^{48}$, desfeitos ao primeiro contato da realidade, qual a derrota de Achilles na corrida com a tartaruga, etc.

Assim, finalmente, é equívoco afirmar que, apesar da devolução, o conflito perdurará, supondo-se, fora dos fatos, dois juízes, dois foros, decidindo ao mesmo tempo a mesma questão, sem ponderar que, normalmente um decide antes, e que essa sentença terá melhor acolhida no outro, se aplicou a lei dêste, e, em geral, pelo princípio corrente do respeito ao direito adquirido no estrangeiro (vide Anteprojeto de Lei Geral, art. 78).

11. Concluindo, os conflitos de normas de DiP, devem ser resolvidos como se resolvem os conflitos de leis civis, comerciais, processuais, etc..

47. Louss Lucas in Revue, 1964, 14, diz que êle fica com o -monople" do caso, e Philonenko com "le pouvoir de commandement" (CLUNET, 1952/184, nota (1).

48. H. VAlladão, A Devolução, cit., p. 66. Também na mecânica os princípios abstratos p. ex., da inércia, de que a tôda reação corresponde uma reação àquela contrária, só funcionam plenamente no vácuo; na realidade o atrito, a fôrça da gravidade impedem o seu funcionamento. Vide, a seguir, o excelente trabalho de Cowan, Renvoi does not involve a logical fallacy in 87 Univ. of Pensilv. L. Review (1938) 34 e ss. 
São conflitos da mesma natureza, no fundo e na realidade, sempre conflitos entre a lei do fôro e a lei estranha.

E devem ser solucionados todos, sem idéias a priori, de excessivo rigor lógico, mas com justiça, eqüidade, sem prevenções discriminatórias contra o DIP estrangeiro, no espírito de harmonia que é o padrão do DIP ${ }^{48 A}$.

48A. O Inst. Dr. Int. em sua 52. ${ }^{\circ}$ Sessão, de Varsóvia, 1965, ñão aprovou o relatório do Prof. Maridakis na $23 .^{\circ}$ Comissão, contrário à devolução; aceitou proposta que redigimos com os Profs. WENGLER e Mraja de la Muela com a adesão de De Nova e Batiffol de dissolver aquela Comissão e criar outra, nova, encarregada dos problemas relativos à "prise en consideration des régles de conflits étrangères", isto é dos casos em que se deverá aplicar o DIP estrangeiro, em geral; quer no conflito positivo, com a renúncia ou princípio da maior proximidade, quer no conflito negativo com a devolução do $1 .^{\circ}$ ou 2. ${ }^{\circ}$ grau. É a vitória da orientação que defendemos desde 1929, $A$ Devolução. e consagramos no Anteprojeto da Lei Geral, arts. 76 e 77; v. págs. $3 / 4,9$ e 18 do presente trabalho, do estudo e resolução conjunta e analógica dos dois problemas. 